\title{
Escrita reflexiva na formação inicial de professores de Matemática: um inventário em dissertações e teses brasileiras
}

\author{
Reflective writing in preservice Mathematics teacher education: an inventory of Brazilian \\ dissertations and theses \\ Escritura reflexiva en la formación inicial de profesores de Matemáticas: un inventario de \\ disertaciones y tesis brasileñas
}

Recebido: 17/09/2021 | Revisado: 24/09/2021 | Aceito: 27/09/2021 | Publicado: 28/09/2021

\author{
Gabriela da Silva Oliveira Vitalino \\ ORCID: https://orcid.org/0000-0002-5378-9960 \\ Secretaria da Educação do Estado de São Paulo, Brasil \\ E-mail: gabrielagsoliveira@gmail.com \\ Bruno Rodrigo Teixeira \\ ORCID: https://orcid.org/0000-0003-0294-4470 \\ Universidade Estadual de Londrina, Brasil \\ E-mail: bruno@uel.br \\ Edilaine Regina dos Santos \\ ORCID: https://orcid.org/0000-0003-2086-4044 \\ Universidade Estadual de Londrina, Brasil \\ E-mail: edilaine.santos@uel.br
}

\begin{abstract}
Resumo
Nesse artigo apresentamos resultados de uma pesquisa desenvolvida com os objetivos de inventariar o que tem sido investigado a respeito da escrita reflexiva no contexto da formação inicial de professores de Matemática, a partir de um levantamento bibliográfico em dissertações e teses brasileiras, e identificar potencialidades da escrita reflexiva presentes nos trabalhos inventariados. Com a intenção de atingir nossos objetivos, realizamos buscas nas plataformas Biblioteca Digital Brasileira de Teses e Dissertações (BDTD) e Catálogo de Teses da Coordenação de Aperfeiçoamento de Pessoal de Nível Superior (CAPES). A partir disso, realizamos uma leitura de cada um dos resumos dos trabalhos obtidos e elencamos aqueles que apresentaram objetivo(s) ou questão(ões) de pesquisa relacionados à escrita na formação inicial de professores de Matemática. Decorrente desses procedimentos, selecionamos seis trabalhos que, a partir de uma exploração, foram organizados em dois eixos temáticos. Considerando os resultados dos trabalhos inventariados identificamos algumas potencialidades dessa escrita reflexiva, tais como, auxiliar futuros professores a mobilizar/desenvolver conhecimentos ou saberes profissionais docentes; compreender o próprio processo de se tornarem professores; (re)significar suas experiências; manifestar aspectos da constituição de sua identidade docente.
\end{abstract}

Palavras-chave: Educação matemática; Formação inicial de professores de matemática; Escrita reflexiva.

\begin{abstract}
This article brings the results of a research carried out with the aim of taking stock of what has been investigated about reflective writing in the context of the preservice mathematics teacher education, based on a bibliographic survey of Brazilian dissertations and theses, and identifying the potential of the reflective writing in the inventoried works. To achieve our goals, we searched the Brazilian Theses and Dissertations Digital Library (BDTD) and Theses Catalog of the Coordination for the Improvement of Higher Education Personnel (CAPES) platforms, after which we read the abstracts of the works obtained and listed those that presented objective(s) or research question(s) related to writing in the preservice mathematics teacher education. From this reading, we selected six works that, based on exploration, were organized into two thematic axes. Considering the results of the inventoried works, we identified some potentialities of this reflective writing, such as helping future teachers to mobilize/develop teacher's professional knowledge; understand the process of becoming a teacher; (re)signify their experiences; manifest aspects of the constitution of their teaching identity.
\end{abstract}

Keywords: Mathematics education; Preservice mathematics teacher education; Reflective writing.

\section{Resumen}

Este artículo trae los resultados de una investigación realizada con el objetivo de hacer un balance de lo investigado sobre la escritura reflexiva en el contexto de la formación inicial de profesores de matemáticas, a partir de un relevamiento bibliográfico de disertaciones y tesis brasileñas, e identificar el potencial de la escritura reflexiva en las obras inventariadas. Para lograr nuestros objetivos, buscamos en la Biblioteca Digital Brasileña de Tesis y 
Disertaciones (BDTD) y el Catálogo de Tesis de las plataformas de Coordinación para el Perfeccionamiento del Personal de Educación Superior (CAPES). Luego, leímos los resúmenes de los trabajos obtenidos y enumeramos los que presentaron objetivo(s) o pregunta(s) de investigación relacionados con la escritura en la formación inicial de los profesores de matemáticas. De esta lectura seleccionamos seis trabajos que, a partir de la exploración, se organizaron en dos ejes temáticos. Teniendo en cuenta los resultados de los trabajos inventariados, identificamos algunas potencialidades de esta escritura reflexiva, como ayudar a los futuros maestros a movilizar/desarrollar saberes o conocimientos docentes profesionales; comprender el proceso de convertirse en un(a) docente; (re)significar sus experiencias; manifestar aspectos de la constitución de su identidad docente.

Palabras clave: Educación matemática; Formación inicial para profesores de matemáticas; Escritura reflexiva.

\section{Introdução}

De acordo com Shum, Sándor, Goldsmith, Bass e McWilliams (2017), a reflexão consiste em um elemento essencial e intrínseco à aprendizagem experiencial em cursos de graduação, entre eles os de formação de professores. No entanto, esses autores destacam que um dos desafios de sua utilização como ferramenta de aprendizagem "é encontrar maneiras pelas quais os estudantes possam demonstrar suas atividades reflexivas". (p. 59, tradução nossa). Uma das maneiras mais comuns tem sido o desenvolvimento de tarefas de escrita reflexiva (Shum et al., 2017).

Embora a escrita reflexiva possa se constituir uma forma comum de implementação de atividades envolvendo a reflexão em diferentes cursos de graduação, pode-se destacar, a partir de trabalhos desenvolvidos por autores como Freitas e Fiorentini (2008) e Leite e Passos (2020), que especificamente na Licenciatura em Matemática no Brasil, o desenvolvimento de uma escrita como essa por parte de futuros professores ainda consiste em uma lacuna desses cursos.

Apesar disso, estudos (Freitas \& Fiorentini, 2008; Lima \& Kochhann, 2018; Antiqueira \& Machado, 2019b; Soares, Gardin \& Santos, 2020; Rodrigues \& Teixeira, 2021; Oliveira \& Teixeira, 2021; Barbosa \& Lopes, 2021; Bonato \& Teixeira, 2021) têm apresentado ações ou instrumentos que podem auxiliar formadores que atuem em cursos de Licenciatura em relação a esse aspecto, e, evidenciado potencialidades de práticas de escrita para a formação inicial de professores de Matemática.

Diante da problemática observada, nesse artigo apresentamos resultados de uma pesquisa desenvolvida com os objetivos de inventariar o que tem sido investigado a respeito da escrita reflexiva no contexto da formação inicial de professores de Matemática, a partir de um levantamento bibliográfico em dissertações e teses brasileiras, e identificar potencialidades da escrita reflexiva presentes nos trabalhos inventariados.

Para isso, na sequência apresentamos aspectos dos procedimentos metodológicos adotados na pesquisa. Posteriormente, de maneira breve cada um dos trabalhos selecionados. E, por fim, resultados e discussões, além de considerações finais

\section{Aspectos Metodológicos}

Como destacado anteriormente, nesse artigo apresentamos resultados de uma pesquisa desenvolvida com os objetivos de inventariar o que tem sido investigado a respeito da escrita reflexiva no contexto da formação inicial de professores de Matemática, a partir de um levantamento bibliográfico em dissertações e teses brasileiras, e identificar potencialidades da escrita reflexiva presentes nos trabalhos inventariados. No entanto, consideramos de suma importância fazer alguns apontamentos de modo a justificar a realização dessa pesquisa frente a outra já desenvolvida em uma perspectiva semelhante.

A pesquisa desenvolvida por Antiqueira e Machado (2019a) teve por objetivo "apresentar um mapeamento de dissertações e teses originadas de cursos de pós-graduações stricto sensu brasileiras e que abordam a prática da linguagem escrita em espaços de formação de professores de Matemática." (p.144). Apesar de temática e objetivo próximos aos que apresentamos nesse artigo, nosso trabalho se diferencia do das autoras pela intenção de considerar no corpus, de maneira específica, dissertações e teses que investigaram algum aspecto associado à escrita reflexiva de futuros professores de Matemática. Autores como Rivera (2017, p. 55, grifo da autora, tradução nossa), destacam que a reflexão é um processo "em 
que se exploram propositalmente seus pensamentos, sentimentos, ações, processos, experiências e circunstâncias, bem como sua lógica subjacente" e, assim, para que seja reflexiva, a escrita "deve mostrar conexão pessoal; caso contrário, é, basicamente, uma redação acadêmica" (Rivera, 2017, p. 55, tradução nossa).

Diante disso, e, em função dos termos de busca, da base de dados e da época em que a busca foi realizada, obtivemos na constituição do corpus alguns trabalhos em comum e outros diferentes dos que foram apresentados pelas pesquisadoras em seu mapeamento. Do total de seis trabalhos obtidos, três são comuns aos que foram por elas considerados (Freitas, 2006; Teixeira, 2009; Caporale, 2016) e outros três não (Pereira, 2014; Cosmo, 2015; Lima, 2017).

Com a intenção de atingir nossos objetivos, realizamos buscas ${ }^{1}$ nas plataformas Biblioteca Digital Brasileira de Teses e Dissertações (BDTD)² e Catálogo de Teses da Coordenação de Aperfeiçoamento de Pessoal de Nível Superior (CAPES) ${ }^{3}$.

As buscas nessas plataformas foram feitas por meio das expressões "escrita", "formação inicial” e "matemática", entre aspas e separadas pela palavra "AND”. Optamos pelo termo "escrita” e não pela expressão "escrita reflexiva”, uma vez que, desse modo, podemos identificar trabalhos que não apresentam a expressão em sua integralidade, mas que, mesmo assim, podem ter relação com o nosso tema de pesquisa.

Por meio dessas buscas, tivemos acesso aos resumos de 149 trabalhos. Desses, 62 a partir da busca no Catálogo de Teses da CAPES e 87 a partir da busca na Biblioteca Digital de Teses e Dissertações. Dos 62 trabalhos obtidos a partir do Catálogo de Teses da CAPES, 26 também foram identificados na busca na BDTD. Dos 87 trabalhos obtidos na busca na BDTD, 1 era repetido, assim, essa busca resultou em 86 trabalhos. Portanto, obtivemos um total de 122 trabalhos.

Para selecionar os que comporiam nosso inventário, lemos cada um desses resumos e elencamos aqueles que apresentaram objetivo(s) ou questão(ões) de pesquisa relacionados à escrita na formação inicial de professores de Matemática. Ainda que não mencionassem a expressão "escrita reflexiva", selecionamos os que possuíam objetivos ou questões cuja ênfase envolvia a escrita, a fim de identificar posteriormente se apresentavam ou não relação com a referida escrita.

Decorrente desses procedimentos, selecionamos 6 trabalhos ${ }^{4}$, apresentados no Quadro 1, em ordem cronológica de publicação.

Quadro 1 - Trabalhos selecionados para compor o inventário.

\section{Teses e dissertaç̃es selecionadas}

Freitas, M. T. M. (2006). A escrita no processo de formação contínua do professor de Matemática (Tese de doutorado, Universidade Estadual de Campinas, Campinas, SP, Brasil)

Teixeira, B. R. (2009). Registros escritos na formação inicial de professores de Matemática: uma análise sobre a elaboração do Relatório de Estágio Supervisionado (Dissertação de mestrado, Universidade Estadual de Londrina, Londrina, PR, Brasil).

Pereira, B. G. (2014) Professores em formação inicial no gênero Relatório de Estágio Supervisionado: um estudo em licenciaturas paraenses (Dissertação de mestrado, Universidade Federal do Tocantins, Araguaína, TO, Brasil).

Cosmo, T. (2015). Escritas de licenciandos em Matemática, quanto à docência, no contexto do PIBID (Dissertação de mestrado, Universidade Federal de São Carlos, São Carlos, SP, Brasil)

Caporale, S. M. M. (2016). Escrever e compartilhar histórias de vida como práticas de (auto) formação de futuros professores e professoras de matemática. (Tese de doutorado, Universidade São Francisco, Itatiba, SP, Brasil).

Lima, V. S. A. (2017). Tecendo a constituição identitária do professor de Matemática narrado nos Memoriais (Dissertação de mestrado, Universidade do Estado de Mato Grosso, Barra do Bugres, MT, Brasil)

Fonte: Autores.

\footnotetext{
${ }^{1}$ As buscas foram realizadas no dia 25 de março de 2021.

${ }^{2} \mathrm{http} / / / \mathrm{bdtd}$.ibict.br/

${ }^{3} \mathrm{http}: / /$ bancodeteses.capes.gov.br/

${ }^{4}$ Desses trabalhos, 2 foram encontrados apenas na busca realizada no Catálogo de Teses da CAPES (Caporale, 2016; Lima, 2017) e 4 foram encontrados tanto na busca realizada no Catálogo de Teses da CAPES quanto na busca realizada na BDTD (Freitas, 2006; Teixeira, 2009; Pereira, 2014; Cosmo, 2015).
} 
Após a seleção dos trabalhos, realizamos uma leitura completa dos mesmos, com a intenção de explorá-los e, assim, identificar elementos como seus objetivos e/ou questões de pesquisa, seus participantes e instrumentos, bem como alguns resultados obtidos por eles. A partir disso, constituímos eixos temáticos tendo em vista semelhanças entre os trabalhos selecionados no que diz respeito a utilização da escrita reflexiva, ou de instrumentos que possibilitam seu desenvolvimento na formação inicial de professores de Matemática.

\section{Sobre as Investigações}

Nessa seção, apresentamos algumas informações a respeito dos trabalhos selecionados para a composição do inventário sobre o que tem sido investigado a respeito da escrita reflexiva no contexto da formação inicial de professores de Matemática.

Freitas (2006, p. ix) teve como objetivo de sua tese

[...] investigar como estudantes do Curso de Licenciatura, futuros professores, participam e respondem à experiência de uma disciplina de formação matemática com uma proposta diferenciada, que privilegia o registro escrito de seus pensamentos e idéias, durante o processo de formação.

Assim, buscou responder as seguintes questões de investigação:

Que contribuições a inserção de diferentes formas de comunicação - especialmente a escrita - em uma disciplina de conteúdo específico (Geometria) traz à formação e ao desenvolvimento profissional do professor de Matemática? Como acontece, nesse processo, a constituição da identidade profissional? (Freitas, 2006, p. 2).

A disciplina em foco foi a intitulada Geometria Plana e Desenho Geométrico, do curso de Licenciatura em Matemática da Universidade Estadual de Campinas, ofertada no primeiro semestre do ano de 2003. Entre os alunos desta turma, a autora selecionou quatro para um acompanhamento mais pormenorizado e perspicaz.

A partir de diversos registros escritos dos alunos, como relatórios, bilhetes, cartas, projetos, autobiografias e mensagens eletrônicas, bem como de entrevistas e questionários, Freitas (2006) construiu uma narrativa de formação para cada um dos participantes.

Quanto aos resultados da pesquisa, a autora destaca que as narrativas "trouxeram à tona, em diferentes graus de proeminência, aspectos importantes da presença da escrita na constituição pessoal e profissional de cada professor" (Freitas, 2006, p. 272). Segundo Freitas (2006, p. 1), essa presença foi favorecida pela prática da escrita discursiva e reflexiva, "isto é, não estritamente simbólica ou formal", promovida pela disciplina de Geometria e também pela de Prática de Ensino de Matemática. Desse modo, esclarece:

A escrita na Prática de Ensino contribuiu para que o professor em formação compreendesse melhor a complexidade das práticas escolares e o próprio processo de vir a ser professor de Matemática neste contexto. Mas foi a escrita, na disciplina de Geometria, associada à utilização de tecnologias de informação e comunicação e ao desenvolvimento de projetos, que contribuiu, de um lado, para promover processos metacognitivos sobre a aprendizagem da Matemática e, de outro, para produzir outros sentidos à Matemática - seus conceitos e processos -, sobretudo quando os interlocutores tinham pouca familiaridade com a linguagem formal. (Freitas, 2006, p. 273).

Freitas (2006, p. 273) ressalta, ainda, que a experiência com a escrita discursiva sobre a Matemática "influenciou a prática futura dos professores, pois estes passaram também a explorá-la didático-pedagogicamente com seus alunos". Além disso, a autora evidencia que alguns desenvolveram uma atitude mais reflexiva e investigativa sobre a própria prática, em virtude da escrita de seus alunos em aulas exploratório-investigativas. 
Outra contribuição destacada por Freitas (2006, p. 273) é a de que a escrita dos pensamentos e ideias permitiu "aos (futuros) professores que seus conhecimentos docentes, às vezes ditos como tácitos, fossem identificados, problematizados e (re)significados". Também propiciou que "(re)significassem seu modo de atuar e organizar o trabalho pedagógico, empenhando-se para que a liberdade de expressão no ambiente de ensino-aprendizagem se fizesse presente na busca de produção de significados" (Freitas, 2006, p. 274).

Em sua dissertação, Teixeira (2009, p. 14) objetivou "investigar a participação da elaboração do Relatório de Estágio Supervisionado na formação inicial de professores de Matemática, na ótica de estudantes do curso de Licenciatura em Matemática da Universidade Estadual de Londrina - UEL”. Desse modo, definiu as seguintes questões:

Que argumentos favoráveis podem ser apresentados com relação à elaboração do Relatório de Estágio Supervisionado na formação inicial de professores de Matemática? Que informações presentes no Relatório podem contribuir para o desenvolvimento profissional de futuros professores de Matemática em formação inicial? Quais as principais dificuldades apresentadas pelos graduandos durante a elaboração do Relatório? (Teixeira, 2009, p. 45).

Na instituição contexto de sua pesquisa, Teixeira (2009, p. 49) esclarece que, para a elaboração do referido Relatório, sugere-se que os estagiários "descrevam os fatos ocorridos durante as aulas ministradas [...], bem como a sua avaliação crítica e suas reflexões sobre os fatos descritos", sendo disponibilizado um roteiro que pode ser considerado para guiar a escrita.

Os participantes da pesquisa foram alunos do $4^{\circ}$ ano da Licenciatura em Matemática da UEL do ano de 2007. A opção por essa turma "ocorreu pelo fato de os estudantes já terem vivenciado a elaboração do Relatório de Estágio Supervisionado no $3^{\circ}$ ano (2006) e de terem no $4^{\circ}$ ano mais uma oportunidade de experienciar esta tarefa" (Teixeira, 2009, p. 46).

A fim de coletar informações que o auxiliassem a cumprir seu objetivo, o autor utilizou questionário, entrevista e diário de campo como instrumentos.

Diante disso, aponta que os futuros professores apresentaram como principal argumento favorável à elaboração do Relatório, o processo de reflexão desencadeado pela sua produção, que os fez refletir acerca da própria prática, de incidentes críticos e do modo como os alunos pensaram e agiram. Destaca, também, que essa elaboração permitiu que os estagiários autoavaliassem sua atuação como professores, o que oportunizou, por exemplo, a identificação de pontos fortes e fracos nessa atuação.

Ademais, Teixeira (2009, p. 67) identificou que, de acordo com os participantes da pesquisa, o Relatório possui informações que podem contribuir para o desenvolvimento profissional de futuros professores de Matemática "em aspectos relativos aos conteúdos matemáticos, às dificuldades encontradas pelos estagiários em lidar com situações didáticas vivenciadas enquanto professores, ao planejamento de aulas e à dinâmica da aula". Assim, indica que este "pode constituir-se um importante instrumento formativo, enquanto elemento de pesquisa a graduandos do curso de Licenciatura em Matemática que venham a ter acesso ao mesmo" (Teixeira, 2009, p. 81).

Em relação às dificuldades provenientes da própria elaboração do Relatório de Estágio Supervisionado, os futuros professores enfatizaram a referente à "escrita discursiva relativa às situações ocorridas no estágio, e aos conceitos matemáticos e idéias relacionadas aos mesmos" (Teixeira, 2009, p. 75).

Nesse sentido, Teixeira (2009, p. 81) acrescenta que

[...] o Relatório pode ser um meio que permita ao futuro professor de Matemática exercitar a escrita discursiva expressando suas idéias acerca de situações ocorridas no estágio de forma crítica e reflexiva. Pode permitir também que escrevam de forma não predominantemente técnica e simbólica sobre os conceitos matemáticos e idéias relacionadas aos mesmos [...]. 
Além da pesquisa de Teixeira (2009), outra que faz parte do corpus de nossa investigação e que também teve como foco o Relatório de Estágio Supervisionado foi a desenvolvida por Pereira (2014, p. 18), que se propõe a

Caracterizar o gênero Relatório de Estágio Supervisionado (doravante RES), a partir da análise das representações de aluno-mestre semiotizadas no texto dos relatórios das licenciaturas em Letras - Língua Portuguesa, em Pedagogia e em Matemática, ofertadas pela Universidade do Estado do Pará (UEPA), localizada no município de Conceição do Araguaia.

Segundo o autor, a análise de Relatórios elaborados nessas licenciaturas "se justifica pelo fato de terem sido as únicas que, na ocasião da coleta dos dados, apresentaram relatórios armazenados na instituição" (Pereira, 2014, pp. 33-34).

Assim, foram analisados os Relatórios produzidos entre os anos de 2010 e 2012 pelos licenciandos, denominados alunos-mestre pelo autor, ao final de disciplinas "destinadas ao período de regência em sala de aula em escolas da Educação Básica" (Pereira, 2014, p. vii).

Pereira (2014) explicita que, em sua pesquisa, a escrita de Relatórios de Estágio Supervisionado é considerada como uma escrita reflexiva profissional, a qual caracteriza, a partir do trabalho desenvolvido por Melo, Gonçalves e Silva (2013), como uma "escrita desenvolvida a respeito das singularidades profissionais, com vistas a uma reflexão mais consistente e crítica da prática pedagógica que se refere" (Pereira, 2014, p. 15).

A partir de suas análises, aponta que, o futuro professor,

[...] mesmo reconhecendo teoricamente a importância do Estágio Supervisionado em sua formação, ainda apresenta uma escrita fortemente burocratizada no que se refere ao relatório de estágio. Isso é bastante pertinente, partindo do princípio de que pouco refletem sobre o que deveras foi vivenciado na escola campo, apresentando uma escrita predominantemente narrativa/descritiva. (Pereira, 2014, p. 123).

Aliado a isso, o autor salienta que, ainda que no gênero Relatório de Estágio seja preciso recontar o que foi vivenciado, "também é necessário articular os fatos recontados às especificidades do ensino da licenciatura que o aluno-mestre pertence" (Pereira, 2014, p. 124). Desse modo, recomenda que, o contexto universitário em questão, "deve retrabalhar sua concepção de escrita, especialmente no que se refere à prática de produção de relatório de estágio, de maneira a oferecer melhores possibilidades para produção deste gênero textual" (Pereira, 2014, p. 126). Apesar disso, destaca que:

[...] os alunos-mestre demonstraram conhecimento a respeito dos procedimentos da escrita reflexiva profissional, porém ainda incipiente. Dessa maneira, [...] os alunos-mestre das licenciaturas focalizadas podem desenvolver trabalhos bastante lucrativos por meio de sua escrita, desde que sejam incentivados ao aprimoramento dessa habilidade. (Pereira, 2014, p. 126).

Em sua dissertação, Cosmo (2015, p. 14, grifo da autora) apresentou a seguinte questão de pesquisa e o seguinte objetivo:

[...] De que modo a docência é expressa nas escritas de futuros professores de matemática, enquanto estão inseridos no PIBID? Assim, temos por objetivo analisar as escritas de futuros professores de matemática, quanto à docência, enquanto inseridos no contexto do PIBID. ${ }^{5}$

Diante disso, no contexto de uma Universidade pública do interior do estado de São Paulo, a autora define "como fonte de dados os registros escritos dos participantes enquanto bolsistas do PIBID, isto é, seus portfólios semestrais, nos quais são relatadas as atividades desenvolvidas pelos bolsistas no âmbito do programa" (Cosmo, 2015, p. 10).

Vale salientar que, de acordo com Cosmo (2015, p. 82),

${ }^{5}$ PIBID - Programa Institucional de Bolsa de Iniciação à Docência. 
[...] os bolsistas recebem a orientação de que seus portfólios devem conter o planejamento de todas as atividades realizadas, incluindo os planos de aula, cuja estrutura é fornecida pelos coordenadores, e ainda as sínteses didáticas da execução das atividades, as quais devem conter suas reflexões. Além disso, cada bolsista deve elaborar um jogo a cada semestre, o qual deve ser apresentado também no portfólio.

A autora destaca que seis indivíduos, entre bolsistas e ex-bolsistas, aceitaram participar da pesquisa, mas, tendo em vista que notou que alguns portfólios "davam mais subsídios para a análise do que outros, pois enquanto alguns sujeitos traziam apenas descrições em seus portfólios, outros indicavam, além das descrições, suas reflexões” (Cosmo, 2015, p. 87), selecionou três para seguir nas análises.

Quanto aos seus resultados, Cosmo (2015, p. 171) evidencia que “os futuros professores apresentam uma ampla compreensão sobre o trabalho docente quando estão inseridos no PIBID, visto que os participantes expressaram a docência extensivamente em suas escritas", apresentando produções acerca de, por exemplo,

[...] conhecimentos pedagógicos; experiência; planejamento, adaptação e improvisação; socialização; contextualização; uso de materiais e tecnologias; adversidades; aprendizagem dos alunos; avaliação da aprendizagem; disciplina; falta de recursos; e intenção da educação. (Cosmo, 2015, p. 172).

Outro trabalho selecionado para o inventário foi a tese de Caporale (2016) que, ao ter como participantes futuros professores e uma professora de Matemática que atuava na Educação Básica, objetivou responder à questão: “Como o(a)s futuro(a)s professores(as) e a professora em exercício vão atribuindo sentido às suas experiências e constituindo a identidade docente, ao participar de práticas de (auto)formação compartilhadas?” (Caporale, 2016, p. 78).

Os participantes da pesquisa integravam um grupo pertencente ao PIBID, cuja orientação era realizada pela autora. Os futuros professores elaboravam, para a disciplina de Estágio Supervisionado, um Memorial de Formação, que foi adotado “como meio de promover a (auto)formação dos futuros professores, oferecendo a eles a (res)significação das suas experiências do passado, que, ao serem rememoradas, se tornavam presentes” (Caporale, 2016, p. 77). Para subsidiar essa escrita, Caporale (2016, p. 46) ressalta que eram propostas leituras de textos a respeito de Memoriais e havia momentos de leitura e reflexão de Memoriais escritos, a fim de que os futuros professores se apropriassem "do gênero textual narrativo e de suas possibilidades formativas". Nesse contexto, ao tomar conhecimento dessa elaboração dos Memoriais pelos futuros professores, a professora em exercício na Educação Básica, supervisora do PIBID, que participava do grupo do programa orientado pela autora optou por produzi-los também.

Diante disso, e considerando que "o ciclo da (auto)formação não se completa apenas com a escrita e com as reflexões sobre as experiências; é necessário que também se mobilize o pensar sobre o pensar" (Caporale, 2016, p. 77), a pesquisadora convidou os sujeitos mencionados para participar de um grupo voltado exclusivamente à socialização e reflexão dos Memoriais, com a intenção de realizar uma "mediação biográfica, ou seja, o acompanhamento da escrita do memorial" (Caporale, 2016, p. 77), o que, segundo ela,

[...] ocorreu em dois momentos: ao fazer a leitura e deixar comentários, com o objetivo de ajudar os sujeitos a pensar sobre alguma experiência em particular, que [...] julgava merecer um pouco mais de atenção; e pela forma oral, no grupo de socialização/reflexão. (Caporale, 2016, p. 77).

Caporale (2016, p. 119) esclarece que, as escritas autobiográficas de seus participantes, caracterizadas como Memoriais de Formação, "contêm algumas das experiências de vida pessoal e de formação profissional dos sujeitos - aquelas que, por algum motivo nem sempre possível de desvelar, foram escolhidas para compô-lo". 
A partir de instrumentos como as conversas no grupo, os memoriais e seu diário de campo, Caporale (2016, pp. 232233) evidencia que, os futuros professores e a professora em exercício,

[...] ao participarem de uma prática de (auto)formação mediada pela escrita - que, por sua vez, mobilizou o processo reflexivo sobre as experiências vividas -, produziram saberes para eles próprios e para a comunidade científica, compartilhando voluntariamente as suas histórias.

Acrescenta, ainda, que

Ao buscar as experiências do passado, algumas num tempo cronológico mais distante, outras ocorridas no dia da própria escrita, trazendo-as para o presente, num movimento de idas e vindas, puderam (re)significá-las, transformar os sentimentos, projetando-se para o futuro. (Caporale, 2016, pp. 233-234).

Outra investigação também desenvolvida a partir de Memoriais de Formação foi a de Lima (2017), que buscou responder,

[...] Como se constitui a Identidade Docente emergida a partir da produção de Memoriais de Formação de licenciandos em Matemática da Universidade do Estado de Mato Grosso (UNEMAT), Campus de Barra do BugresMT, desenvolvidos durante os Estágios Curriculares Supervisionados I e II do periodo de 2016/2 e 2017/01? (pp. 1617 , grifo da autora).

Assim, estabelece o seguinte objetivo geral:

[...] Investigar, na formação inicial de professores, o processo de constituição da identidade docente, que emerge a partir da produção dos Memoriais de Formação dos licenciandos de Matemática, da Universidade do Estado de Mato Grosso-(UNEMAT), Campus de Barra do Bugres - MT, desenvolvidos durante os Estágios Curriculares Supervisionados I e II, realizados, respectivamente, nos períodos de 2016/02 e 2017/01. (Lima, 2017, p. 17).

Entre seus objetivos específicos, tem-se: “Analisar se os Memoriais de Formação podem ser instrumentos de reflexão do processo de formar-se professor, na perspectiva dos licenciandos" (Lima, 2017, p. 17).

Tendo como participantes cinco licenciandos, Lima (2017) analisou os Memoriais escritos por eles, os quais foram produzidos durante disciplinas de Estágio, uma em que realizaram apenas observação na escola e outra em que atuaram como professores regentes em sala de aula.

Segundo a autora, houve momentos de orientação para a elaboração dos Memoriais, em que foram apresentados aportes teóricos a respeito de Memorial de Formação, bem como exemplares de Memoriais prontos, a fim de "contribuir com a escrita crítica e reflexiva dos textos solicitados" (Lima, 2017, p. 27). Além disso, as produções seguiam roteiros com questões que norteavam a escrita. Após sua entrega e apresentação, os Memoriais foram devolvidos para que os licenciandos pudessem reescrevê-los e apresentar mais reflexões.

Entre seus resultados, Lima (2017, p. 129) aponta que

[...] por meio da produção dos Memoriais podemos, por um lado, compreender como os licenciandos estão se formando e constituindo sua identidade docente [...]; e por outro, [...] perceber a importância dos Memoriais para os licenciandos, pois a partir deles podem refletir sobre sua experiência de vida ao longo de sua formação, ressignificando-a e compreendendo como vem aos poucos se constituindo, se tornando professor.

Nesse sentido, ressalta que o Memorial "como instrumento de formação tem seu potencial pela escrita reflexiva, em que o licenciando faz uma reflexão, diferente da oralidade, porque há uma estruturação, e essa estruturação pode fazer compreender e ressignificar a sua própria formação" (Lima, 2017, p. 132).

Ademais, Lima (2017, p. 132) enfatiza que 
[...] se faz necessário pontuar o papel do roteiro para produção do Memorial, como orientador do processo da escrita deste documento reflexivo na formação, que pode auxiliar os licenciandos na produção dos Memoriais; o papel do formador que pode orientar e acompanhar essas produções incentivando as escritas reflexivas dos licenciandos; o papel da reescrita dos Memoriais, onde os licenciandos podem perceber elementos e momentos de sua formação que passaram despercebido, ressignificando-os; e o papel do estágio como cenário desse processo de produção dos Memoriais, utilizando este espaço como lugar de uma formação reflexiva dos licenciandos.

\section{Resultados e Discussões}

Tendo em vista semelhanças entre os trabalhos selecionados no que diz respeito a utilização da escrita reflexiva, ou de instrumentos que possibilitam seu desenvolvimento na formação inicial de professores de Matemática, constituímos os seguintes eixos temáticos:

Quadro 2 - Eixos temáticos.

\begin{tabular}{|l|l|}
\hline \multicolumn{1}{|c|}{ Eixo temático } & \multicolumn{1}{|c|}{ Investigações } \\
\hline $\begin{array}{l}\text { Escrita reflexiva como objeto de investigação e suas contribuições para a } \\
\text { formação/desenvolvimento profissional docente }\end{array}$ & $\begin{array}{l}\text { Freitas (2006) } \\
\text { Teixeira (2009) } \\
\text { Pereira (2014) }\end{array}$ \\
\hline $\begin{array}{l}\text { Escrita reflexiva como meio para investigar aspectos específicos da formação } \\
\text { docente }\end{array}$ & $\begin{array}{l}\text { Cosmo (2015) } \\
\text { Caporale (2016) } \\
\text { Lima (2017) }\end{array}$ \\
\hline
\end{tabular}

Fonte: Autores.

O primeiro eixo temático diz respeito à "Escrita reflexiva como objeto de investigação e suas contribuições para a formação/desenvolvimento profissional docente" e engloba os trabalhos de Freitas (2006), Teixeira (2009) e Pereira (2014). A partir de seus resultados evidenciamos potencialidades dessa escrita para auxiliar futuros professores a mobilizar/desenvolver conhecimentos profissionais docentes (Freitas, 2006), a (re)pensar a respeito de suas práticas e da dinâmica das aulas (Freitas, 2006; Teixeira, 2009), a compreender o próprio processo de se tornarem professores (Freitas, 2006), e a escrever sobre conteúdos matemáticos de uma maneira não apenas simbólica ou formal (Freitas, 2006; Teixeira, 2009). Além disso, o trabalho de Pereira (2014) nos permite evidenciar como potencialidade da caracterização da escrita reflexiva presente em Relatórios de Estágio Supervisionado, por exemplo, orientar formadores de professores em relação a aspectos em que podem oferecer suporte aos licenciandos durante a proposição de tarefas tendo em vista o desenvolvimento desse tipo de escrita.

Os trabalhos que constituem o eixo "Escrita reflexiva como meio para investigar aspectos específicos da formação docente" (Cosmo, 2015; Caporale, 2016; Lima, 2017) nos permitem vislumbrar, por exemplo, portfólios (Cosmo, 2015) e memoriais (Caporale, 2016; Lima, 2017) elaborados por futuros professores de Matemática como fonte de informações para se investigar aspectos de sua formação tais como sua compreensão acerca do trabalho docente (Cosmo, 2015) e a constituição de sua identidade docente (Caporale, 2016; Lima, 2017), oportunizando aos licenciandos também manifestarem conhecimentos (Cosmo, 2015) ou saberes profissionais (Caporale, 2016), bem como (re)significarem suas experiências (Caporale, 2016; Lima, 2017).

Além das potencialidades da escrita reflexiva de futuros professores descritas a partir dos eixos temáticos constituídos, resultados apresentados nesses trabalhos inventariados possibilitam realçar outros aspectos referentes a sua utilização na formação inicial de professores de Matemática. Por exemplo, que esse tipo de escrita pode contribuir para o desenvolvimento profissional dos futuros professores e para que se possa investigar esse desenvolvimento, tendo em vista que, segundo autores como Ponte e Oliveira (2002), o desenvolvimento profissional do professor ocorre em dois campos intimamente relacionados, quais sejam, o do conhecimento e o da identidade profissional docente, os quais puderam ser 
evidenciados mediante a escrita reflexiva produzida por licenciandos a partir de diferentes instrumentos, conforme sínteses dos resultados de pesquisas aqui apresentadas.

Ademais, a escrita reflexiva oportuniza ao futuro professor se conscientizar do seu próprio processo formativo. Nesse sentido, concordamos com o que destacam Barbosa e Lopes (2021), especificamente tendo em vista o contexto do Estágio Curricular Supervisionado (ECS), mas que consideramos que possa se estender para outras ações da formação inicial:

Ao produzirem escritas reflexivas de si e do seu processo de formação no ECS - a partir da interação com os outros (os professores, os alunos, a pesquisadora e os colegas), com a escola e consigo mesmo -, os futuros professores se apropriaram do seu próprio poder de formação, tomaram consciência de seus saberes e começaram a se identificar como professores. (Barbosa \& Lopes, 2021, p. 18)

Apesar de a utilização da escrita reflexiva ter sido mais comum em contextos como Estágio Curricular Supervisionado e PIBID, pode ser proposta por formadores em diversas disciplinas do curso, considerando a possibilidade e a importância de o futuro professor desenvolver uma escrita a respeito de conteúdos matemáticos que possa ajudar na comunicação em sala de aula com seus futuros alunos, especialmente os que apresentam dificuldades com uma linguagem predominantemente formal ou simbólica.

Por fim, pode-se destacar a relevância e a necessidade de os formadores auxiliarem os futuros professores no desenvolvimento de uma escrita reflexiva, seja por meio da discussão de referenciais teóricos que permitam a eles compreenderem o que caracteriza esse tipo de escrita, seja mediante a utilização de roteiros que possam orientá-los em suas produções escritas, roteiros esses que sejam dinâmicos e ao serem analisados cuidadosamente a partir de tais referenciais teóricos e mediante as produções dos licenciandos possam ser modificados sempre que necessário para incentivar o desenvolvimento de uma escrita reflexiva (Oliveira \& Teixeira, 2021). Além disso, de oportunizarem aos futuros professores a socialização e problematização dessas escritas tendo em vista suas potencialidades formativas.

\section{Considerações Finais}

Nesse artigo apresentamos resultados de uma pesquisa desenvolvida com os objetivos de inventariar o que tem sido investigado a respeito da escrita reflexiva no contexto da formação inicial de professores de Matemática, a partir de um levantamento bibliográfico em dissertações e teses brasileiras, e identificar potencialidades da escrita reflexiva presentes nos trabalhos inventariados.

Por meio das buscas realizadas nas plataformas Biblioteca Digital Brasileira de Teses e Dissertações (BDTD) e Catálogo de Teses da Coordenação de Aperfeiçoamento de Pessoal de Nível Superior (CAPES), selecionamos 6 trabalhos para compor o inventário que, a partir de uma exploração, permitiu organizá-los em dois eixos temáticos: "Escrita reflexiva como objeto de investigação e suas contribuições para a formação/desenvolvimento profissional docente" e "Escrita reflexiva como meio para investigar aspectos específicos da formação docente".

A partir dos resultados dos trabalhos inventariados identificamos algumas potencialidades dessa escrita reflexiva. Em relação aos futuros professores, essas potencialidades estão relacionadas, por exemplo, à:

- mobilizar/desenvolver conhecimentos ou saberes profissionais docentes;

- (re)pensar a respeito de suas práticas e da dinâmica das aulas;

- compreender o próprio processo de se tornarem professores;

- (re)significar suas experiências;

- escrever sobre conteúdos matemáticos de uma maneira não apenas simbólica ou formal;

- manifestar sua compreensão a respeito do trabalho docente; 
- evidenciar aspectos da constituição de sua identidade docente.

No que diz respeito aos formadores, identificou-se que a escrita reflexiva dos licenciandos pode orientá-los em relação a aspectos em que podem oferecer suporte durante a proposição de tarefas a esses futuros professores tendo em vista o desenvolvimento desse tipo de escrita.

Diante disso, consideramos que escrever reflexivamente a respeito de diferentes ações e nos mais diversos contextos da formação inicial, tendo o suporte necessário por parte dos professores formadores, pode auxiliar os futuros professores em seu desenvolvimento profissional docente e ser foco de investigações futuras.

\section{Referências}

Antiqueira, L. S. \& Machado, C. C. (2019a). Prática da linguagem escrita em espaços de formação de professores de Matemática: mapeamento de pesquisas produzidas no Brasil. Revista de Ensino de Ciências e Matemática, 10(1), 144-163.

Antiqueira, L. S. \& Machado, C. C. (2019b). A Linguagem Escrita Proporciona um "Espaço de Encontro" no PIBID Matemática: Processos Interativos e Coletivos Potencializados. JIEEM, 12(1), 38-50.

Barbosa, C. P. \& Lopes. C. E. (2021). Saberes mobilizados por futuros professores de Matemática em suas narrativas no estágio. EM TEIA - Revista de Educação Matemática e Tecnológica Iberoamericana, 12 (1), 1-23.

Bonato, G. V. \& Teixeira. B. R. (2021). Conhecimentos evidenciados na Escrita Reflexiva de Futuros Professores de Matemática a Respeito de um Planejamento de Aula. Educação Matemática em Revista-RS, 22 (1), 97-108.

Caporale, S. M. M. (2016). Escrever e compartilhar histórias de vida como práticas de (auto) formação de futuros professores e professoras de matemática. (Tese de doutorado, Universidade São Francisco, Itatiba, SP, Brasil).

Cosmo, T. (2015). Escritas de licenciandos em Matemática, quanto à docência, no contexto do PIBID (Dissertação de mestrado, Universidade Federal de São Carlos, São Carlos, SP, Brasil)

Freitas, M. T. M. (2006). A escrita no processo de formação contínua do professor de Matemática (Tese de doutorado, Universidade Estadual de Campinas, Campinas, SP, Brasil)

Freitas, M.T. M., \& Fiorentini, D. (2008). Desafios e potencialidades da escrita na formação docente em matemática. Revista Brasileira de Educação. 13 (37), $138-149$.

Leite, E. A. P. \& Passos, C. L. B. (2020). Considerações sobre lacunas decorrentes da formação oportunizada no curso de Licenciatura em Matemática no Brasil. Revista de Educação Pública, 29, 1-23.

Lima, V. S. A. (2017). Tecendo a constituição identitária do professor de Matemática narrado nos Memoriais (Dissertação de mestrado, Universidade do Estado de Mato Grosso, Barra do Bugres, MT, Brasil)

Lima, V. S. A. \& Kochhann, M. E. R. (2018). Tecendo a constituição identitária do professor de matemática narrado nos memoriais. ACTIO, 3 (1), $184-204$.

Melo, L. C., Gonçalves, A. V., Silva, W. R. (2013). Escrita acadêmica na escrita reflexiva profissional: citações de literatura científica em relatórios de estágio supervisionado. Bakhtiniana, 8 (1), 95-119.

Oliveira, G. S \& Teixeira, B. R. (2021). Potencialidades para a escrita reflexiva de futuros professores de Matemática em um roteiro de elaboração de Relatório de Estágio de Observação. Revista Paranaense de Educação Matemática, 10(21), 235-258.

Pereira, B. G. (2014) Professores em formação inicial no gênero Relatório de Estágio Supervisionado: um estudo em licenciaturas paraenses (Dissertação de mestrado, Universidade Federal do Tocantins, Araguaína, TO, Brasil).

Ponte, J. P. \& Oliveira, H. (2002). Remar contra a maré: A construção do conhecimento e da identidade profissional na formação inicial. Revista de Educação, $11(2), 145-163$

Rivera, R. (2017). The reflective writing continuum: Re-conceptualizing Hatton \& Smith's types of reflective writing. International Journal of Research Studies in Education, 6 (2), 49-67.

Rodrigues, A. L. \& Teixeira, B. R. (2021). Conhecimento especializado do professor de Matemática revelado na escrita reflexiva de futuros professores decorrente de simulações de aulas. Revista de Ensino de Ciências e Matemática, 12(3), 1-26.

Shum, S. B., Sándor, A., Goldsmith, R., Bass, R. \& McWilliams, M. (2017). Towards reflective writing analytics: Rationale, methodology, and preliminary results. Journal of Learning Analytics, 4(1), 58-84.

Soares, N. M. S., Gardin, F. S. \& Santos, E. R. (2020). A escrita reflexiva na formação de professores de Matemática. South American Journal of Basic Education, Technical and Technological, 7(2), 950-958.

Teixeira, B. R. (2009). Registros escritos na formação inicial de professores de Matemática: uma análise sobre a elaboração do Relatório de Estágio Supervisionado (Dissertação de mestrado, Universidade Estadual de Londrina, Londrina, PR, Brasil). 